\title{
REFLEXÕES SOBRE A POLÍTICA SOCIAL A PARTIR DO CONTEXTO MONETÁRIO INTERNACIONAL: UMA DISCUSSÃO PRELIMINAR
}

\author{
W. G. Silva'; S. C. Silva ${ }^{2}$ e J. S. Figueiredo ${ }^{3}$ \\ ${ }^{1,3}$ Departamento de Economia - Universidade do Estado do Rio Grande do Norte \\ ${ }^{2}$ Licenciatura em Geografia - Instituto Federal do Rio Grande do Norte \\ williangledson@gmail.com - susilva_oi@yahoo.com.br - jonilsonufrn@yahoo.com.br
}

Artigo submetido em julho/2012 e aceito em março/2013

\section{RESUMO}

Este trabalho teve o objetivo de analisar os efeitos da política econômica (notadamente à monetária) em nível global sobre as políticas sociais, cujo mecanismo de transmissão foi à via fiscal. Metodologicamente, tratouse de uma pesquisa essencialmente bibliográfica, configurando-se em um estudo exploratório com vestígios explicativos. Finalmente, verificou-se que as políticas econômicas de natureza monetária refletem a formulação de políticas sociais internalizadas no local, cuja forma de repercussão foi expressa no contexto fiscal, permitindo evidenciar, de modo preliminar, o constatado neste estudo.

PALAVRAS-ChAVE: Política Econômica, Contexto Fiscal, Política Social.

\section{REFLECTIONS ABOUT SOCIAL POLICY FROM INTERNATIONAL MONETARY CONTEXT: A PRELIMINARY DISCUSSION}

\section{ABSTRACT}

This work aimed to analyze the effects of economic policy (notably the monetary) at the global level on social policies, whose mechanism of transmission was via taxation. Methodologically, it was essentially a search, bibliographic in configuring an exploratory study with explanatory traces. Finally, it was found that the monetary economic policies reflect the formulation of social policies in place, internalized repercussion was expressed in the tax context, allowing evidence, so preliminary, the study found.

KEY-WORDS: Economic Policy, Fiscal Context, Social Policy. 


\section{REFLEXÕES SOBRE A POLÍTICA SOCIAL A PARTIR DO CONTEXTO MONETÁRIO INTERNACIONAL: UMA DISCUSSÃO PRELIMINAR}

\section{INTRODUÇÃO}

Uma das importantes discussões presentes na academia é a dicotomia Estado ou mercado, isto é, as inúmeras pesquisas não atingiram até os dias atuais um consenso sobre o papel estatal no natural funcionamento do mercado, ao contrário, essa discordância alcança níveis cada vez maiores de divergência.

Assim, Brunhoff (1978) destaca a dialética teórica entre a perspectiva neoliberal e a vertente keynesiana, de modo que essas correntes se opõem fortemente quanto ao entendimento do funcionamento da economia capitalista, notadamente no que concerne à presença da via estatal no circuito econômico, seja na produção seja na circulação. ${ }^{1}$

Nesse sentido, Friedman (1985), que se constitui como um dos principais expoentes das ideias antagônicas ao Estado, cuja prerrogativa teórica está alicerçada no neoliberalismo, doutrina essa defensora do livre funcionamento das forças de mercado, sem a preocupação com as camadas sociais, tão inexpressivas economicamente, quando se considera a capacidade de consumo dos agentes, através do seu poder aquisitivo ${ }^{2}$.

Contrariamente, notam-se formulações teóricas mais inclinadas a negação do neoliberalismo, admitindo ser no seio do Estado, a única possibilidade real de superação das desigualdades cristalizadas na sociedade, cujo mecanismo palpável a esse fim decorre das formulações das políticas de natureza social (BRUNHOFF, 1985). ${ }^{3}$

No plano econômico por sua vez, verifica-se uma profunda contradição no funcionamento do Estado, o qual deve ser para os neoliberais fundamentalmente conservadores, sem a propensão a gastar mais do que se arrecada, ao paço que orientações teóricas como as que se manifestam em Keynes (1985), sugerem uma participação bastante incisiva da via estatal dentro

\footnotetext{
${ }^{1}$ A ideia de intervenção do Estado no plano produtivo se relaciona as atividades de produção propriamente ditas, já no campo da circulação, esse se refere a uma interferência nas relações de troca em torno da mercadoria.

${ }^{2}$ A diferença entre neoliberalismo e o liberalismo do ponto de vista do seu corpo doutrinário, decorre de uma maior inclinação neoliberal em favor do mercado (por meio das privatizações, por exemplo), minimizando a ação do Estado, sendo contundentemente contrário a qualquer ideia de limitação das livres forças de mercado, um ideário significativamente mais rígido que o liberalismo. Além disso, ressalte-se que o neoliberalismo passa a ser uma corrente de pensamento que eclode no pós-guerra, sendo uma forte oposição ao ideário socialista soviético, conforme Anderson (2008).

${ }^{3}$ A autora expressa que as chamadas políticas sociais podem ser conhecidas também como políticas salariais ou de emprego, de acordo com a conveniência, conceito essencial ao atual trabalho.
} 
da economia, defendendo inclusive a realização de gastos (ainda que elevados) para a dinamização da atividade econômica através do princípio da demanda efetiva. ${ }^{4}$

Nessas condições, esse embate possibilita a reflexão das chamadas políticas sociais em um ambiente socioeconômico caracterizado pela supremacia do mercado frente ao Estado, em outras palavras a hegemonia do capital comanda as diversas relações sociais, nas quais a burguesia expropria o proletariado, cujo papel estatal no referido processo, é tão somente garantir esse cenário de desigualdade.

Com efeito, essa desigualdade caracteriza o sistema capitalista, sendo pretensão deste artigo analisar como as políticas públicas direcionadas ao social podem minorar essa dicotomia sistêmica, embora o Estado encerre em si o poder da classe dominante. Logo, o contexto econômico atual influencia decisivamente os contornos das políticas orientadas às camadas sociais menos favorecidas, cuja preocupação é examinar como se dá esse processo, do ponto de vista da forma em que o contexto global respinga na dimensão local.

Nesse sentido, o problema ressaltado pode ser sintetizado: a política econômica em uma dimensão global (de natureza monetária) apresenta vestígios de influências sobre as políticas sociais localizadas, através do contexto fiscal?

A hipótese é, portanto, que as mudanças na política monetária (fundamentalmente por meio das taxas de juros) alterem o comportamento fiscal dos países, particularmente os federados, cuja consequência é o reflexo desse processo nas formulações e execuções de políticas sociais no local e caso o ambiente econômico esteja estável, há tendências mais plausíveis às políticas localizadas. Já na instabilidade por seu turno, esse efeito é de igual modo negativo.

Este estudo pode ser justificado por algumas razões palpáveis, isto é, o cenário atual da economia capitalista explicita inúmeras condições, no tocante as disparidades regionais e sociais, as quais tendem a repercutir diferentemente nos distintos espaços. De fato, o plano teórico motiva a construção da presente reflexão, sendo um estímulo apriorístico.

Além disso, nota-se haver certa inconsistência teórica na relação entre o movimento econômico no plano global em face às formulações e execuções das políticas sociais, tomando-se como referência a moeda (equivalente geral), passando pelo contexto fiscal de países federados

\footnotetext{
${ }^{4}$ Formulação teórica que explicita serem os gastos os determinantes da renda, ou seja, os agentes decidem gastar e por isso geram renda, o contrário da Lei de Say, que assevera haver uma determinação dos gastos através da renda, sendo a oposição teórica do princípio da demanda efetiva, de acordo com Silva (1999).
} 
como o Brasil, influenciando a dimensão local, na tentativa de compreender como se configura esse processo.

Portanto, o objetivo central deste artigo é analisar as repercussões das políticas econômicas globais (especialmente a monetária) sobre as políticas sociais locais (peculiarmente municípios), cujo mecanismo de transmissão desses efeitos se trata da via fiscal.

Metodologicamente, fundamenta-se este trabalho em uma pesquisa essencialmente bibliográfica, de modo a realizar um estudo exploratório e explicativo, cuja expectativa é fornecer ao final da análise, uma contribuição capaz de produzir inquietações para investigações futuras, notadamente de natureza aplicada.

Finalmente, este artigo se encontra dividido em mais três seções além da introdução. A seguir, faz-se uma discussão sobre a política econômica, a qual se desenvolve do contexto monetário ao fiscal, manifestando seu efeito em uma federação; na sequência, apresenta-se uma reflexão sobre a influência dessas políticas na formulação e execução de políticas sociais no plano local; reserva-se, por fim, para última seção as considerações finais e as eventuais recomendações aos futuros trabalhos.

\section{CONSIDERAÇÕES SOBRE A GESTÃO ESTATAL DA POLÍTICA ECONÔMICA}

Esta seção tem por objetivo discutir, de modo breve, aspectos da política econômica em uma sociedade de cunho capitalista, a qual legitima uma estrutura de classes, em que a burguesia (detentora do capital em termos marxistas) domina as demais classes a exemplo do proletariado.

Isso posto, pretende-se concentrar a discussão sobre a moeda (equivalente geral) conforme denomina Brunhoff (1985), na condição de um elemento vital ao processo de acumulação burguesa, que é conservada pelo Estado e capaz de influenciar a formulação das políticas sociais em nível local.

Faz-se necessário esclarecer a relação entre moeda e gestão pública, especialmente, no que se refere a uma Federação como é o caso do Brasil. Silva (2009), por sua vez, mostra que existem estruturas administrativas públicas unitárias, em que há países com o poder político 
administrativo centralizado, ao passo que se podem notar federações com um determinado nível de descentralização ${ }^{5}$ da gestão pública.

A comunicação fiscal entre as unidades de uma Federação se dá através da distribuição de recursos e/ou competências, cujo ponto de partida decorre da União (por exemplo) para os municípios, podendo ser mais ou menos intensa essa descentralização, iniciando-se pela repartição de recursos e após as competências, ou vice-versa, conforme Affonso (2003). Assim, para efeitos analíticos deste trabalho é importante observar qual a relação estabelecida entre o contexto monetário e o fiscal?

Em primeiro lugar, faz-se importante explicitar que a moeda ${ }^{6}$ é entendida como meio de troca, ou através dela as mercadorias podem manifestar o seu valor no processo de troca no âmbito do mercado, a partir de Brunhoff (1985). Logo, cada nação deve desenvolver um elemento capaz de permitir as relações de compra e venda entre os agentes (SILVA, 1999).

Em segundo lugar, ressalte-se que existem diversas nações, as quais estabelecem relações econômicas por meio de moedas que se equiparam, isto é, como cada país administra sua própria moeda, essas devem ser comparadas no mercado específico monetário, (mercado de câmbio $^{7}$ que permite a troca de um tipo de equivalente geral por outro, quando um agente de uma nação necessita realizar uma transação econômica em um país que não é aquele em que reside (BLANCHARD, 2004).

Nessas condições, qual a importância do equivalente geral no contexto fiscal? É válido salientar que a moeda dentro de um sistema econômico capitalista é endógena, quer dizer, o gestor monetário afeta sorrateiramente a quantidade de meios de pagamento (papel moeda em poder do público e os depósitos a vista) na economia, ou seja, a chamada liquides sistêmica é definida de fato pelo capital bancário, em que esse através dos empréstimos, determina o volume dos meios de pagamento. (SILVA, 1999; WRAY, 2003).

Assim, a política econômica, que na verdade é uma ação estatal para conservar o poder da burguesia, de acordo com Brunhoff (1985), é definida nas palavras de Wray (2003, p. 118 -

\footnotetext{
${ }^{5}$ Esse conceito expressa que o governo Central transfere autonomia e recursos aos gestores subnacionais, os quais possuem poder decisório para formular e aplicar políticas públicas.

${ }^{6}$ A moeda, do ponto de vista de sua concepção, assume a condição de meio de troca, unidade de conta e reserva de valor, sendo um elemento crucial para chamada economia de produção e monetizada.

${ }^{7}$ É um mercado no qual se compara moedas de diferentes países; a taxa de câmbio, portanto, significa a compra de uma unidade monetária de uma nação por determinada quantidade de moeda de outra, mudando essa paridade através das forças de mercado (oferta e demanda).
} 
119): "política fiscal tem mais a ver com a quantidade de moeda e com o valor da moeda, enquanto a política monetária simplesmente determina as taxas de juros de overnight".

Com efeito, Franco (2006) e Silva (2009) mostram que o contexto fiscal de uma economia tende a provocar reflexos monetários. Isso se deve ao fato de que a administração pública, ao realizar um volume de gastos elevado e que, normalmente, supera a arrecadação tributária, gera uma consequência capaz de produzir o chamado déficit público, cuja repercussão monetária é o surgimento da inflação, através da tentativa de financiar o déficit com emissão de moeda via títulos da dívida.

A argumentação anterior revela que a gestão estatal, caso produza significativos déficits públicos, pode acarretar forte ambiente inflacionário ${ }^{8}$, visto que, a administração pública deve financiar o déficit, tendo como instrumentos a emissão monetária via títulos ${ }^{9}$ (mecanismo possível de geração de inflação), ou a adoção de políticas de austeridade fiscal $^{10}$ (medida bastante utilizada pelos gestores, conforme pode ser observado na atualidade).

Com efeito, essa constatação é um tanto questionável, pois a solução desse problema não corresponde à realidade. Assim, ressalte-se que a maneira de financiamento desses déficits, supostamente, obtidos por gestões fiscais irresponsáveis, pode ser resolvida através de captação de recursos junto às instituições financeiras (burgueses detentores do capital financeiro), cujo reflexo corresponde a uma elevação de longo prazo da dívida.

A relação que se pode estabelecer com esses aspectos é que se houver expansão do déficit público, que cresce proporcionalmente aos gastos mais elevados, repercutindo na ampliação da dívida, associado a um eventual ambiente inflacionário provocado por emissão monetária para financiar o déficit, a medida dos gestores é elevar os juros básicos da economia, refletindo negativamente do ponto de vista social.

Essa discussão apresenta um fundamento importante a ser ressaltado, no que diz respeito à relação da classe hegemônica e a via estatal, visto que, no capitalismo, a função do Estado se configura na materialização da hegemonia do capital, na condição de uma relação de poder, ou em outras palavras, a instância estatal garante a reprodução burguesa como classe dominante

\footnotetext{
${ }^{8}$ Inflação está associada a um elevado volume de moeda, a chamada inflação de demanda.

${ }^{9}$ O Governo emite moeda ao comprar títulos privados, gerando inflação pelo aumento de liquidez na economia, acarretando um maior contingente de moeda em poder dos agentes, os quais irão realizar maiores gastos na aquisição das mercadorias, gerando inflação.

${ }^{10}$ Significa rigidez na administração das contas públicas, sendo essa mais restritiva, de modo a limitar a isenção de impostos e ou cortes nos gastos públicos, na tentativa de diminuir a possibilidade de inflação de demanda.
} 
manifestada no capital, repercutindo diretamente no proletariado (classe dominada, a qual sofre os efeitos negativos dessa organização) (ANDERSON, 2008; NEVES; PRONKO, 2010).

Dessa forma, saliente-se que o objetivo da acumulação presente na economia capitalista é essencial ao sistema, quer dizer, independentemente da forma de como venha a ocorrer à acumulação, o fundamento é decorrente da ideia da reprodução desse capital, tendo por base ideológica, a continuidade da desigualdade, em que o neoliberalismo é a estrutura de pensamento capaz de firmar tais raízes e que será examinada sua influência social na seção postada a seguir.

Isso posto, faz-se necessário esclarecer que o capital reúne duas formas principais de reprodução: a esfera produtiva ou a financeira. Nessas condições, Keynes (1985) ressalta que existe a chamada eficiência marginal do capital, a qual demonstra haver uma possibilidade de escolha do agente em investir no contexto produtivo ou no financeiro, cujo elemento capaz de influenciar essa escolha corresponde aos juros, de modo que se forem mais elevados que os lucros esperados em uma eventual atividade produtiva associados ao risco contido no ambiente financeiro, migra-se o capital a tal modalidade, sendo o contrário verdadeiro.

De fato, o argumento anterior revela um aspecto apresentado por Neves e Pronko (2010), quando refletem sobre o pensamento de Poulantzas, de modo que segundo essa análise, a formação social capitalista é constituída por classes, essencialmente a burguesia (classe tida como dominante) e o proletariado (classe dominada e explorada pelo capital), em que a classe dominante é fracionada, isto é, a burguesia detém diferentes maneiras de manifestar seu poder diante do proletariado.

Assim, exemplifica-se a fração do capital a partir da didática separação da esfera produtiva e financeira. Assim, na atualidade, nota-se uma preponderância do contexto financeiro em detrimento ao produtivo, visto que em países como o Brasil, o qual foi perdendo parte do seu parque industrial pela ineficiência produtiva, desestatizando-se por meio das privatizações, o resultado mais factível observado gerou uma especialização regressiva (aumento da participação agrícola na economia) (CARNEIRO, 2002).

Com efeito, tal resultado explicitado mostra que houve uma tendência de mudança de composição na estrutura do capital brasileiro, mas que não modificou a dominância da classe burguesa frente ao proletariado, do ponto de vista da fração do capital, entretanto ocorreram 
transformações na forma de acumulação, em que o reflexo desse processo será discutido neste trabalho.

Ressalte-se que o advento do financeirismo na economia capitalista a exemplo do Brasil é factual, isto é, a necessidade de controle fiscal alcança um padrão bastante elevado, sobretudo em nações pouco desenvolvidas (emergentes), embora o discurso se direcione ao contexto global indiscriminadamente. Isso significa que as diferenciações econômicas mundiais determinam distinções no tratamento das políticas a serem praticadas pelos diversos países, conforme é possível compreender em Brunhoff (1985) e Carneiro (2002).

Esse conservadorismo repousa fundamentalmente sobre a política econômica, a qual passa a ser mais restrita nas nações em que o capitalismo ainda é menos competitivo, ou seja, a necessidade de intervenção estatal é mais importante ao contexto social na chamada periferia global $^{11}$ (ARAÚJO, 2000; SOUZA, 2005).

Nesse sentido, as diferenciações existentes no plano social e econômico permitem que a modalidade financeira de acumulação de capital expresse a seguinte forma de influência, no que se refere à política econômica: como a grande parte dos detentores do capital se encontra nas nações centrais, esses países determinam o andamento da especificidade da política das nações menos desenvolvidas.

Diante disso, ressalte-se que em tempos de estabilidade financeira, o sistema capitalista viabiliza relações econômicas prósperas, tanto no plano produtivo, cujos juros se mantêm em níveis menores, elevando-se o volume de investimentos e o aumento no número de postos de trabalho a serem demandados pelos detentores dos meios de produção; já na instabilidade (estágio atual do capitalismo mundial) ${ }^{12}$, os efeitos são contrários, mas a fração do capital ligada à esfera financeira passa a obter lucros significativamente altos, uma vez que os juros na economia como um todo remuneram muito mais que os investimentos produtivos, havendo uma desaceleração na atividade econômica (KEYNES, 1985).

Os ganhos dos burgueses, por sua vez, dão-se pela necessidade dos países menos desenvolvidos em se financiar, pois na instabilidade financeira em escala mundial, o comércio internacional se reduz, elevam-se os déficits externo e fiscal, o crescimento econômico passa a se constituir fundamentalmente através de políticas expansionistas, cujo reflexo imediato é a

\footnotetext{
${ }^{11}$ Essa perspectiva teórica está associada ao pensamento estruturalista, cuja expressão mais contundente dessa teoria se encontra na Comissão Econômica para a América Latina (CEPAL).

${ }^{12}$ Compreensão dos autores diante da instabilidade econômica no limiar no século XXI. 
elevação dos déficits e a busca por financiamentos, tendo como conseqüência o aumento pela ampliação dos juros do ponto de vista sistêmico, repercutindo favoravelmente à fração do capital ligada ao âmbito financeiro.

Em suma, a reflexão construída nesta seção é factível, já que, observou-se a existência de modalidades distintas de acumulação de capital, de modo que as políticas econômicas são utilizadas na conservação da dominação por parte da burguesia, a qual encontrou no contexto financeiro uma alternativa plausível ao processo em discussão. Assim, reserva-se ao próximo item uma reflexão sobre a influência desse plano global em uma perspectiva financeira no tocante ao local, considerando as prováveis consequências ao meio social.

\section{ASPECTOS ANALÍTICOS DAS POLÍTICAS SOCIAIS NO CONTEXTO ECONÔMICO CAPITALISTA}

Esta seção procura discutir as influências dos movimentos financeiros internacionais, cuja moeda é a mentora desse processo, desembocando na chamada gestão social em torno dos espaços mais localizados a exemplo dos municípios brasileiros. Logo, toma-se como referência a vertente neoliberal ${ }^{13}$ para analisar o que vem sendo desenvolvido, do ponto de vista das políticas sociais, na tentativa de aferir o real impacto da política econômica no âmbito geral sobre a dimensão mais restrita.

Com efeito, os instrumentos de política econômica, que estão associados ao contexto monetário e, por conseguinte ao fiscal, refletem na sociedade de modo "perverso", pois a gestão estatal da moeda procura realizar os seguintes aspectos: política de juros altos e restrição na criação de base monetária (para que se evitem choques inflacionários), controle do déficit fiscal, manutenção de taxas elevadas de desemprego como garantia de um estoque de força de trabalho para reduzir o poder sindical.

Nessas condições, faz-se necessário discutir, ainda que de passagem, tais aspectos supracitados. Assim, uma política de juros altos e de contenção de base monetária tem o objetivo de controlar o avanço inflacionário visto que uma maior liquidez na economia tende a provocar possibilidades de aumento na demanda, cuja repercussão é a escalada no nível geral de preços (MODENESI, 2005; SILVA, 2009).

\footnotetext{
${ }^{13}$ Vertente conservadora que tem por receituário ideológico a crença em políticas mais restritivas, defesa de aspectos ligados as desigualdades socioeconômicas, enfim, a preservação do poder da burguesia em detrimento às camadas populares.
} 
Outro ponto é decorrente da ideia de controle fiscal, que se refere à conservação da saúde fiscal de uma gestão pública, cujo reflexo é a redução nos gastos governamentais direcionados ao social, arrefecendo-se o chamado custeio da máquina e aumentando a taxa de investimento público, com vistas a beneficiar o capital, com se verifica em Silva (2009).

Assim, explica-se a manutenção das taxas elevadas de desemprego, a partir de Anderson (2008) cuja teoria é constatada na curva de Phillips. Esse modelo analítico expõe a existência de um dilema entre inflação e desemprego, de modo que se houver desemprego baixo, tão somente é possível com inflação alta, e vice-versa (BLANCHARD, 2004).

De fato, o autor supracitado revela que na versão da curva de Phillips monetarista, desenvolvida por Friedman, a taxa de desemprego é entendida como natural, quer dizer, caso a gestão estatal por meio da política monetária deseje reduzi-la, o único efeito alcançado no chamado longo prazo é o retorno à taxa natural de desemprego combinada com uma taxa de inflação mais elevada.

Dito isso, os argumentos até então explicitados mostram a pujança neoliberal, isto é, essa ideologia tomou conta do sistema capitalista e internalizou nos agentes a grande preocupação de preservar a inflação em patamares mais baixos, deixando a cargo do mercado o ajuste entre oferta e demanda da força de trabalho, de modo que no longo prazo haverá o chamado equilíbrio no mercado de trabalho, sem a necessidade de interferências estatais, que tão somente prolongaria o alcance a esse equilíbrio.

Tal discurso repleto da ideologia burguesa permite a realização de algumas considerações: no plano global, os grandes capitais determinam o viés da política econômica, cujo movimento depende exclusivamente das tendências mercantis, de forma a assegurar a hegemonia da classe dominante; a consequência do calibre na política econômica está associada ao processo de apropriação da mais-valia ${ }^{14}$, em termos marxistas, conservando a manutenção das taxas de lucro em patamares desejados pelo capital.

Logo, as áreas mais dinâmicas do globo (países centrais) ditam o comportamento da forma de gestão da periferia, revelando que essa divisão internacional (entre ricos e pobres) orquestra as políticas, principalmente aquelas mais voltadas ao contexto social. De acordo com o estado do cenário econômico global, pode-se requerer das nações postas à margem, uma maior

\footnotetext{
${ }^{14}$ Significa a apropriação do chamado trabalho não pago, podendo ser caracterizada por absoluta e ou relativa. 
disciplina na formulação das políticas econômicas, cuja forma mais presente de prudência desses países é a dimensão fiscal ${ }^{15}$.

A partir de Brunhoff (1985), entende-se que as políticas sociais tendem a ser um reflexo da dimensão mais geral, conforme o interesse do capital internacional. Daí a grande questão é a seguinte: a política de emprego ou salarial é afetada de qual modo por meio dos movimentos globais?

Todavia, ressalte-se que em um país federado como o Brasil, o qual é diferenciado regionalmente, com base em Araújo (2000), as chamadas políticas de emprego ou salariais são mais adequadamente formuladas no âmbito dos municípios, onde na verdade os gestores locais ofertam postos de trabalho em maior magnitude na forma temporária, os chamados cargos comissionados.

Saliente-se que o pensamento neoliberal respinga nesta dimensão, uma vez que, Gomes e Mac Dowell (1995) argumentam haver no Brasil uma quantidade de entes municipais extremamente pobres, sustentados quase que exclusivamente por transferências intergovernamentais como o FPM $^{16}$, produzindo no seio desses municípios uma gama de postos de trabalhos tidos como improdutivos.

Entretanto, Brunhoff (1985), ao discutir às políticas econômicas, deixa à possibilidade de uma compreensão na qual o marxismo pode minorar tais situações adversas em torno da classe trabalhadora, cuja forma de superação desses antagonismos é a presença mais marcante do Estado, formulando e aplicando políticas sociais, garantindo direitos trabalhistas, realizando eventuais políticas redistributivas de renda, não tendo à excessiva inclinação a preservação da estabilidade de preços $^{17}$.

Já a compreensão keynesiana, fundamentada no princípio da demanda efetiva, permite considerar que a existência de déficits públicos não gera catástrofes nas finanças públicas de uma gestão governamental, mas ao contrário, a realização de gastos tende a conduzir para níveis de

\footnotetext{
${ }^{15} \mathrm{O}$ exemplo a esse argumento se encontra na situação europeia a atual, que para preservar a moeda de curso continental, exige enormes sacrifícios fiscais de nações menos desenvolvidas como é o caso da Grécia, provocando instabilidades políticas e sociais no país, em razão de uma tendência a se reduzir o conjunto das políticas voltadas à sociedade, notadamente as parcelas menos favorecidas.

16 Fundo de Participação dos Municípios é a grande transferência intergovernamental existente no Brasil, correspondendo a $22,5 \%$ de tudo que é arrecadado através de Imposto de Renda (IR) e de Imposto sobre Produtos Industrializados (IPI).

${ }^{17}$ Interpretação própria dos autores. 
crescimento econômico mais altos, replicando-se por todo sistema tal iniciativa de natureza pública, acarretando inclusive elevação na arrecadação como consequência desse processo.

Na verdade, o déficit público, em níveis aceitáveis, produz prosperidade econômica e, portanto, social, tendo em vista a tendência de redução na taxa de desemprego e garantia de renda em circulação na economia, embora essa ação não esteja exclusivamente vinculada aos investimentos de ordem infraestruturais ${ }^{18}$, propiciando a geração de mais renda como reflexo via efeito multiplicativo (ARAúJO, 2006).

Do ponto de vista do pensamento neoliberal, faz-se necessário recordar que a ideia de controle fiscal é preponderante, cujo exemplo factível no Brasil é a chamada Lei de Responsabilidade Fiscal ${ }^{19}$, a qual se propõe à disciplinar as finanças públicas das várias instâncias governamentais no país, na tentativa de reduzir os déficits e, portanto, conter a ampliação na dívida dos governos dos diversos entes federativos.

A partir do já exposto, pode-se atestar que o neoliberalismo, na condição de uma ideologia, assume um papel exponencial na condução da formulação e execução das políticas de cunho social, visto que, os gestores situados na dimensão local passam a ser reféns das decisões postadas no âmbito global, isto é, o capital internacional, mediante seus próprios interesses, fornece os encaminhamentos de política econômica (mais precisamente a monetária), cujo reflexo no país se apresenta de maneira conservadora, arrefecendo-se o poder das políticas orientadas ao social.

Afinal, o equivalente geral comanda as diversas formas de política, seja no contexto econômico, seja na esfera social, permitindo que se observe a clara relação de dominância interclasse, tendo na moeda esse elemento vital para o processo de reprodução ampliada do capital $^{20}$, ou mesmo a influência dessa na formulação de políticas fiscais e ou sociais, repercutindo em uma maior ou menor empregabilidade e, por conseguinte, a constituição de uma massa de indivíduos capazes de se reproduzir socialmente.

\footnotetext{
18 Os chamados gastos públicos impulsionam a economia, tanto na modalidade dos investimentos, como nos custeios; isso significa que gastos com consumo também geram demanda e são capazes de gerar prosperidade às camadas sociais, principalmente aquelas menos favorecidas.

${ }^{19}$ A LRF, criada em maio de 2000, é entendida como a maior expressão institucional repousante sobre as finanças públicas brasileiras conforme Silva (2009).

${ }^{20}$ Conceito esse que está associado a ideia do dinheiro, mercadoria, mais dinheiro, ou seja, o capitalista retira da circulação mais dinheiro que investiu inicialmente, sendo o elemento responsável para tal fim a chamada absorção da mais-valia dos burgueses ao expropriarem o proletariado.
} 
Em suma, a dimensão local é dramaticamente influenciada pelo âmbito global, cujo mecanismo de transmissão dos efeitos da política social internalizadas no local se dá pelas flutuações monetárias no contexto econômico internacional, repercutindo de forma intermediária na gestão fiscal, sendo essa a responsável por transferir a estabilidade ou instabilidade do plano geral ao restrito, aspecto por demais corriqueiro no sistema capitalista.

\section{CONSIDERAÇÕES FINAIS}

Após a discussão até então desenvolvida, que teve por objetivo a análise dos efeitos das políticas econômicas globais (particularmente a monetária) sobre as políticas sociais em nível local (especificamente municípios), cujo mecanismo de transmissão dessas influências correspondeu a esfera fiscal, o qual foi possível pelo exame da literatura fundamental a esta pesquisa que permitiu o alcance do aqui proposto.

Com efeito, notou-se que a gestão estatal da moeda, no plano nacional, sofre incontestáveis modificações (mudanças na condução da política monetária) decorrentes das flutuações internacionais, sobretudo em momentos de instabilidade no cenário econômico global. Tais contingências são provenientes dos interesses do grande capital internacional.

Esse desenho constante em todo sistema capitalista é repousante no contexto doméstico de cada país, cuja primária preocupação dos gestores se encontra no controle fiscal, tendo por finalidade minorar os reflexos da economia como um todo na nação, reduzir as possibilidades de ascensão inflacionária, preservar o valor da moeda doméstica e, fundamentalmente, garantir a classe dominante um ambiente favorável.

Finalmente, o contexto da política econômica afeta, decisivamente, o plano social, de modo que as chamadas políticas voltadas às camadas sociais passam a ser influenciadas, visto que os gestores locais, quase que tão somente, reproduzem o cenário global na dimensão mais restrita dos espaços nacionais (por exemplo os municípios), em virtude das oscilações no volume de recursos originários das instâncias governamentais superiores.

Portanto, a hipótese teórica proposta neste trabalho pode ser aceita, isto é, de fato as políticas sociais internalizadas no local são um produto do plano internacional, sendo indispensável por tal razão que os gestores locais busquem atuar mais próximos das camadas menos favorecidas da sociedade, tentando reduzir conflitos de classe, procurando formular 
políticas que possam combinar avanços sociais e não alteração dos interesses capitalistas, afinal, torna-se preponderante criar mecanismos capazes de diminuir as chamadas desigualdades sociais e a única via para tal prerrogativa corresponde ao Estado.

Assim, sugere-se para futuros trabalhos o aprofundamento da revisão de literatura, especialmente, a discussão da relação global e local; além disso, recomenda-se a consideração de uma região como é o caso da área metropolitana de Natal, visto que essa já é objeto de vários estudos das mais diversas naturezas, mas que a proposta apresentada nessas páginas ainda não foi foco de reflexões sobre essa região.

\section{REFERÊNCIAS}

1. AFFONSO, R. de B. A. O Federalismo e as Teorias Hegemônicas da Economia do Setor Público na Segunda Metade do Século XX: um balanço crítico. Tese (Doutorado em Economia) Instituto de Economia, Campinas, 2003.

2. ANDERSON, P. Balanço do Neoliberalismo. In: GENTILI, P; SADER, E. (Org.). Pósneoliberalismo: as políticas sociais e o estado democrático. 8.ed. São Paulo: Paz e terra, 2008. p. 9-23.

3. ARAÚJO, T. B. Ensaio sobre o desenvolvimento brasileiro: heranças e urgências. Rio de Janeiro: Revan Fase, 2000.

4. ARAÚJO, H. V. de. Análise Comparativa do Gasto Social Brasileiro por Índices de Retornos Tributários. In: PRÊMIO DO TESOURO NACIONAL, IX, 2006. Brasília. Disponível em: <http://www3.tesouro.fazenda.gov.br/Premio_TN/XIpremio/qualidade/1qualidadeXIPTN/r esumo.htm>. Acesso em: 15 jul 2012. Brasília: ESAF, $2006.54 p$

5. BLANCHARD, O. Macroeconomia. 3.ed. São Paulo: Prentice Hall, 2004.

6. BRUNHOFF, S. de. Crise capitalista e política econômica. In: POULANTZAS, Nicos. (Dir.). A crise do Estado. Lisboa: Moraes Editores, 1978.

7. . Estado e capital: uma análise da política econômica. Rio de Janeiro: Forence, 1985.

8. CARNEIRO, R. Desenvolvimento em crise: a economia brasileira no último quarto do século XX. São Paulo: Editora UNESP, 2002.

9. FRANCO, G. H. B. Crônicas da Convergência: ensaios sobre temas já não tão polêmicos. Rio de Janeiro: Editora Topbooks, 2006.

10. FRIEDMAN, M. Capitalismo e Liberdade. 2. ed. São Paulo: Nova Cultura, 1985.

11. KEYNES, J. M. A Teoria Geral, do Emprego, do Juro e da Moeda. São Paulo: Nova Cultural, 1985.

12. SILVA, A.C. M. E. Macroeconomia sem Equilíbrio. Petrópolis: RJ Editora Vozes, 1999. 
13. GOMES, G. M.; MAC DOWELL, M. C. Os Elos Frágeis da Descentralização: observações sobre as finanças dos municípios brasileiros. In: Seminário Internacional sobre Federalismo e Governos Locais, 1995, La Plata. Anais... Argentina, 1995.

14. MODENESI, A. M. Regimes Monetários. Bauru: Manole, 2005.

15. NEVES, M. L.; PRONKO, M. A atualidade das idéias de Nicos Poulantzas no entendimento das políticas sociais no século XXI. Germinal: Marxismo e Educação em Debate, Londrina, v.1, n.2, jan. 2010.2 P.97-111. Disponível em: http://www.uel.br/revistas/uel/index.php/germinal/article/view/4277/3458. Acesso em: 15 jul 2012.

16. SILVA, W. G. Finanças públicas na nova ordem constitucional brasileira: uma análise comportamental dos municípios potiguares nos anos antecedentes e posteriores a Lei de Responsabilidade Fiscal (LRF). Dissertação (Mestrado em Economia) - Universidade Federal do Rio Grande do Norte, Natal, 2009.

17. SOUZA, N. Desenvolvimento Econômico. São Paulo: Atlas, 2005.

18. WRAY, R.L. Trabalho e moeda hoje: a chave para o pleno emprego e a estabilidade dos preços. Rio de Janeiro: Editora UFRJ/Contraponto, 2003. 